\title{
Facile Fabrication of Quaternized Sisal Fiber by Electron Beam Radiation and its Effective Adsorption for Indigo Carmine from Aqueous Solution
}

Jifu Du

Hubei University Of Science and Technology

Dongcheng Fan

Hubei University Of Science and Technology

Zhen Dong

Huazhong University of Science and Technology

Xin Yang

Hubei University Of Science and Technology

Long Zhao ( $\nabla$ zhaolong@hust.edu.cn )

Huazhong University of Science and Technology https://orcid.org/0000-0002-6126-2210

\section{Research Article}

Keywords: Sisal fiber, Indigo Carmine, Adsorption, Radiation grafting

Posted Date: January 21st, 2022

DOI: https://doi.org/10.21203/rs.3.rs-1228301/v1

License: (c) (i) This work is licensed under a Creative Commons Attribution 4.0 International License.

Read Full License 


\section{Abstract}

The removal of Indigo carmine (IC) from the aquatic environment is necessary due to its high toxicity. In this study, methacryloxy ethyltrimethyl ammonium chloride (DMC) modified sisal fiber (SF-DMC) was prepared by a one-step process using radiation induced grafting polymerization. The adsorption performance of SF-DMC toward IC dye was investigated by batch adsorption experiments. The adsorption kinetic studies shows that adsorption equilibrium reached within $30 \mathrm{~min}$, and it can be well described by pseudo-second-order model. The adsorption isotherms are well described by Langmuir model, and the theoretical maximum adsorption capacity are 709.22 to $892.86 \mathrm{mg} / \mathrm{g}$ at different temperature. The adsorption of IC onto SF-DMC is a spontaneous and exothermic reaction and low temperature is favorable for adsorption. Besides, SF-DMC has good selective adsorption for IC in the mixed anionic dyes and in high-salt solution. The dyes on SF-DMC can be desorbed by $2 \mathrm{~mol} / \mathrm{L} \mathrm{HCl}$ solution. Therefore, the SF-DMC exhibits excellent adsorption performance, which is suitable for IC removal from high-salt wastewater.

\section{Introduction}

Indigo Carmine (IC) is a synthesized anionic dye that is widely used as a colorant in foods, cosmetics and dyeing of clothes (blue jeans) (Ketes et al., 2020). The inappropriate release of IC from large-scale use throughout dyeing process will cause environmental problem and severe harm on human health due to its high toxicity (Gopi et al., 2017; Ahmed et al., 2017). Thus, the removal of IC from the aquatic environment is considered to be necessary (Ahmad et al., 2021). Various methods are used to remove IC from effluents, including membranes (Gopi et al., 2017), chemical oxidation (Shu et al., 2016), photo-catalysis (Secula et al., 2020), electro-catalytic (Lei et al., 2021) and biological methods (Borba et al., 2020). However, the application of the mentioned processes is limited because of the relatively high operational costs, low efficiency, greater energy consumption, and sludge generation.

Adsorption is considered as one of the most simple and attractive methods to purify polluted water (Chowdhury et al., 2020; Du et al., 2021). In recent years, the low cost adsorbents based on natural fibers have been recognized as efficient, cost-effective, and environmental friendly for contamination removal purposes (Candido et al.,2021). Owing to small fiber diameter and excellent osmotic stability, the plant based cellulose fibers have been widely investigated for the adsorption of pollutants, including radionuclides (Bai et al., 2020; Li et al., 2020), heavy metals (Huang et al., 2021; Pang et al., 2020), humic acid (Du et al., 2019), phosphate (Du et al., 2019), dyes (Shao et al., 2021), gold ions (Mostofa et al., 2021) and oil/water separation (Meng et al., 2020; Liu et al.,2018) et al. Plant-based cellulose fibers such as sisal, jute, hemp, coir, kapok, cattail, and cotton linter display lots of advantages over synthetic fibers like low-cost, low density, biodegradability, recyclability, environment friendly, and less hazardous over synthetic fibers (Chokshi et al., 2020; Cui et al., 2021; Zheng et al., 2020; Silva et al., 2020). Among them, sisal fiber (SF) is a most noteworthy and industrially promising fibers have attracted particular interest due to its fairly coarse, moderate high specific strength and stiffness, durability, and resistance to deterioration in saltwater (Tesfamariam et al., 2019). The main component of SF is cellulose, which mass 
proportion of cellulose accounts for $73 \%$ (Filho et al., 2020). Cellulose possesses a reactive surface which bears hydroxyl groups make it very suitable to be chemical modified and used as adsorbent.

The modification of fiber matrix has attracted increasing attention, which are relevant strategies to improve the adsorption performance of plant fibers. Various methods such as carbonization (Melike et al., 2018), plasma treatment (Silva et al., 2020), chemical deposition (Tesfamariam et al., 2019), microwave treatment (Gao et al., 2015) and electron or y-ray radiation techniques (Dong et al., 2021) are used for fiber modification. Specifically, radiation-induced graft polymerization (RIGP) can conveniently introduce the required functional groups onto polymer surface and then endow the polymers with densely accessible adsorption sites ( Du et al., 2018).

Electrostatic attractions have been shown to be an effective and versatile force to treat ionic contamination. The quaternary amine type adsorbents are the most commonly used adsorbent for anionic dye removal because of the strong electrostatic reaction between the amine group and the anionic sulfonate group of the dye molecule. The synthesis routes are usually carried out by the modification of primary amine, followed by quaternization (Du et al., 2019; Talet et al. 2008; Wang et al., 2019; Song et al., 2019). The syntheses of these adsorbents are cumbersome and require several steps, which need to be simplified. To our knowledge, if appropriate monomer and synthesis method were devised, facile fabrication of adsorbent will be obtained.

In this paper, we attempted to synthesize a low cost and environmental friendly adsorbent by an one step process through grafting methacryloxy ethyltrimethyl ammonium chloride (DMC) onto SF. Considering the unique advantages of the high stability, ordered hydrophobic pore channels and densely accessible cationic sites, the adsorption performance of SF-DMC are expected to be good for anionic dyes. So, batch adsorption experiments of SF-DMC toward IC were conducted. The effects of solution $\mathrm{pH}$, dosage, adsorption time, initial concentration, ion strength and the coexisted dyes on the adsorption of SF-DMC for IC were studied. The adsorbent may provide a useful alternative for industrial dye removal.

\section{Experimental}

\subsection{Materials}

Sisal fiber was obtained from commercial. $\mathrm{DMC}, \mathrm{HCl}, \mathrm{NaOH}$ and IC were obtained from a commercial supplier (Macklin Chemical Reagent Co., Ltd).

\subsection{Preparation of SF-DMC}

SF was boiling treated by $5 \% \mathrm{NaOH}$ for 30 min, washed and dried at $40^{\circ} \mathrm{C}$. SF with mass of $2 \mathrm{~g}$ was vacuum sealed in polyethylene bags. $30 \mathrm{wt} \% \mathrm{DMC}$ aqueous solution was nitrogen-bubbled to remove oxygen in solution. Then $50 \mathrm{~mL}$ DMC solution were extracted using a medical syringe and injected into the bags. The bags were irradiated by the electron beam by an accelerator ( $1 \mathrm{MeV}$, Wasik Associates Inc., 
USA) with the dose rate $10 \mathrm{kGy} /$ pass. The total dose ranged from 0 to $60 \mathrm{kGy}$. After irradiation, the SF were filtered, washed and dried at $40^{\circ} \mathrm{C}$. Thus, SF was functionalized by DMC (SF-DMC).

The grafting yield (GY) was calculated using the mass increase using equation (1):

$$
G Y=\frac{W_{g}-W_{0}}{W_{0}} \times 100 \%
$$

1

where $W_{0}$ and $W_{g}$ are the mass of SF before and after grafting, respectively.

\subsection{Characterization}

Fourier transform infrared spectroscopy (FTIR) spectra was tested by spectrophotometer (Bruker Tensor 27). The morphologies were observed by scanning electron microscope (SEM) (Tescan Vega 3).

Thermogravimetric analysis (TG) curves were recorded using a TGA 55 (TA instruments) with heating rate $10^{\circ} \mathrm{C} / \mathrm{min}$. Zeta potential was tested on a 90 Plus PALS system. The concentration of IC and MO was determined using a UV-vis spectrophotometer (UV-3600, Shimadzu) at $610 \mathrm{~nm}$ and $468 \mathrm{~nm}$, respectively.

\subsection{Batch Adsorption Experiments}

In the $\mathrm{pH}$ effect studies, $0.03 \mathrm{~g}$ of dry SF-DMC was placed in a glass bottle containing $100 \mathrm{~mL}$ of 100 $\mathrm{mg} / \mathrm{L} \mathrm{IC}$ solution. Different $\mathrm{pH}$ values were adjusted by using $0.5 \mathrm{M} \mathrm{HCl}$ or $\mathrm{NaOH}$. In the adsorption kinetic studies, $0.02 \mathrm{~g}$ SF-DMC was used and the adsorption times were $1,3,5,10,15,20,30,60,90$, and 120 min. In the adsorption isotherm studies, $0.02 \mathrm{~g}$ and $100 \mathrm{~mL}$ was used and the IC concentration ranged from 100 to $700 \mathrm{mg} / \mathrm{L}$. The adsorption capacity (Q) and removal percent (R) of SF-DMC to IC was calculated using equation (2) and (3):

$$
Q_{t}=\frac{\left(C_{0}-C_{t}\right) \times V}{m}
$$

2

$$
R=\frac{C_{0}-C_{e}}{C_{0}} \times 100 \backslash \%
$$

3

where $C_{0}$ and $C_{t}$ are the IC concentrations before and after adsorption, respectively; $V$ is the solution volume, and $m$ is the weight of SF-DMC. The averages of triplicate measurements were used as the final adsorption data.

\section{Results And Discussion}

\subsection{Preparation}


Figure 1 shows the effect of radiation dose on the $G Y$ of DMC grafting onto SF. The GY increased with increasing radiation dose, and reached a maximum value of $73 \%$ at $60 \mathrm{kGy}$. This results can be explained by the decay mechanism of trapped radicals. The mechanism of RIGP is mainly a free radical reaction, and the grafting yield is determined by the total free radicals formed both in the monomer solution and the substrate (Zhang et al., 2012). The total free radicals increased with the increasing radiation dose. The grafting polymerization mainly occurs at the interface between monomer and polymers, so, GY finally reached at $60 \mathrm{kGy}$. Moreover, a higher radiation dose will result in the decomposition of cellulose content, thereafter lead the GY decreasing. Then, the SF-DMC with a GY of $73 \%$ was used for further characterization and adsorption studies.

\subsection{Characterization}

FTIR spectra were used to verify the grafting of DMC onto SF (Figure 2a). The spectral bands at 3335, 2917, 1637, and $1036 \mathrm{~cm}^{-1}$ was due to $\mathrm{O}-\mathrm{H}, \mathrm{C}-\mathrm{H}, \mathrm{H}-\mathrm{O}-\mathrm{H}$, and $\mathrm{C}-\mathrm{O}$ bonds of cellulose, respectively (Du et al., 2019b; Chattopadhyay et al., 2017). The band at $1726 \mathrm{~cm}^{-1}$ is the characteristic of the carboxyl group (C=O) ( $\mathrm{Li}$ et al., 2017). The bands at 1470 and $948 \mathrm{~cm}^{-1}$ are the bending vibration of the $\mathrm{C}-\mathrm{N}^{+}\left(\mathrm{CH}_{3}\right)$ in methylene group and DMC, respectively (Yang et al., 2015; Udoetok et al., 2016). The two peaks obtained from the SF-DMC sample confirmed the successfully grafting of DMC onto the SF.

Figure $2 b$ shows the TG analysis of the SF and SF-DMC samples. The weight loss at low temperature (25$100^{\circ} \mathrm{C}$ ) corresponded to water dehydration. For the SF, the weight loss zones were located at $320-380^{\circ} \mathrm{C}$ and $380-580^{\circ} \mathrm{C}$. After DMC grafting, the two weight loss zones located at 250 to $300^{\circ} \mathrm{C}$ and 300 to $450^{\circ} \mathrm{C}$, which appeared at low temperature compared to SF, which corresponding to the decomposition of DMC and cellulose, respectively.

Figure 3 shows the SEM images of SF and SF-DMC. The SF exhibited a fiber bundle structure with diameters about $250 \mu \mathrm{m}$. The lignin and hemi-cellulose were removed by $\mathrm{NaOH}$ treatment and the fiber shape is exposed. After DMC grafting, the fiber bundle splitted into several thinner fibers with diameter of 30-40 $\mu \mathrm{m}$.

\subsection{Dye uptake experiments \\ 3.3.1 pH effect and Zeta potential}

Solution $\mathrm{pH}$ plays a significant role in controlling the adsorption process. The IC adsorption capacity by SF-DMC was tested at various $\mathrm{pH}$ and shown in Figure 4 (a). The adsorption capacity was higher at all the $\mathrm{pH}$ range. The concentration of IC after equilibrium adsorption was nearly zero, which means that all the IC in aqueous solution was completely adsorbed. Zeta potential $(\mathrm{mV})$ of SF-DMC was tested and shown in Figure 4 (b), which were positive at a wide $\mathrm{pH}$ range. So the positive adsorption site will generate strong electrostatic attraction to the anionic $\mathrm{IC}$ molecule at a wide $\mathrm{pH}$ range, thus resulted in the high adsorption capacity with $\mathrm{pH}$ independent.

\subsubsection{Effect of dosage}


Figure 5 (a) displays the dosage effect of SF-DMC on IC adsorption. The IC removal efficiency increased significantly with increase of SF-DMC dosage. This is attributed to the more functional groups of SF-DMC were worked for IC adsorption. The removal efficiency reached $99.8 \%$ at $0.015 \mathrm{~g} / \mathrm{L}$. The adsorption capacity (Qe) was decreased with increase of the SF-DMC dosage and it was $500 \mathrm{mg} / \mathrm{g}$ at dose $0.2 \mathrm{~g} / \mathrm{L}$. In this study, the dosage $(0.02 \mathrm{~g}$ SF-DMC in $100 \mathrm{~mL} I C)$ was conducted for further experiment.

\subsubsection{Adsorption Kinetics: Effect of Contact Time}

Figure 5 (b) shows the adsorption kinetics with the initial concentration of $100 \mathrm{mg} / \mathrm{L}$. It can be seen that the adsorption capacity increases with increasing contact time and the adsorption process reached equilibrium at $30 \mathrm{~min}$. Three models, pseudo-first-order (equation 4), pseudo-second-order model (equation 5), and intra-particle diffusion model (equation 6) were used to evaluate the adsorption kinetics. The initial adsorption rate $h_{0}(\mathrm{mg} / \mathrm{g} \cdot \mathrm{min})(t \rightarrow 0)$ was expressed as equation (7) (Hadid et al., 2021).

$$
\begin{aligned}
& Q_{t}=Q_{e}\left(1-e^{-k_{1} t}\right) \\
& Q_{t}=\frac{k_{2} Q_{e}^{2} t}{1+k_{2} Q_{\mathrm{e}} t} \\
& Q_{t}=k_{\mathrm{p}} t^{1 / 2}+I \\
& h_{0}=k_{2} Q_{\mathrm{e}}^{2}
\end{aligned}
$$

where $Q_{t}$ and $Q_{e}$ are the amounts of IC adsorbed per gram SF-DMC at time $t$ and at the equilibrium time, respectively.

Table 1 presents the values of the linear correlation coefficient $\left(R^{2}\right), Q_{e} k_{1}$, and $k_{2}$. Comparison of these values showed that the $R^{2}$ of the pseudo-second-order model was higher than that of the pseudo-firstorder model. The pseudo-second-order model described the kinetic data well (Figure $5 c$ ), suggesting that the IC adsorption onto the SF-DMC was a chemical adsorption process (Wu et al., 2021). The adsorption capacity was $500 \mathrm{mg} / \mathrm{g}$, calculated using the pseudo-second-order model, which was in accordance with the experimental data.

The kinetic data is also described using the intra-particle diffusion model and the Weber-Morris plots are shown in Figure 5 (d). The plot is not straight, but presents multiply distinct regions. According to this model, the first and second linear parts corresponded to surface diffusion and intra-particle diffusion and the third region mean equilibrium adsorption. The first linear part did not pass through the origin, suggesting that intra-particle diffusion is not the sole rate determining step (Du et al., 2020). 
Table 1

Kinetic parameters obtained from kinetics model of the SF-DMC

\begin{tabular}{|c|c|c|}
\hline \\
\hline Kinetic model & Parameters & Values \\
\hline \multirow[t]{3}{*}{ Pseudo-first-order } & $\mathrm{K}_{1}$ & 0.7068 \\
\hline & $\mathrm{Q}_{\mathrm{e}}$ & 473.13 \\
\hline & $\mathrm{R}^{2}$ & 0.9346 \\
\hline \multirow[t]{4}{*}{ Pseudo-second-order } & $\mathrm{K}_{2}$ & 0.0023 \\
\hline & $\mathrm{Q}_{\mathrm{e}}$ & 500.00 \\
\hline & $\mathrm{R}^{2}$ & 0.9998 \\
\hline & ho & 571.43 \\
\hline \multirow[t]{6}{*}{ Intra-particle diffusion } & $\mathrm{R}^{2}$ & 0.9982 \\
\hline & $\mathrm{K}_{\mathrm{p} 1}$ & 164.20 \\
\hline & l & 7.2148 \\
\hline & $\mathrm{R}^{2}$ & 0.9171 \\
\hline & $\mathrm{K}_{\mathrm{p} 2}$ & 30.484 \\
\hline & l & 357.08 \\
\hline
\end{tabular}

\subsubsection{Adsorption Isotherms: Effect of initial concentration}

The adsorption isotherms were used to describe the distribution of target compounds between the solid and liquid phase at equilibrium. Figure 6 (a) shows the experimental data along with the fitted isotherm model curves of IC adsorption onto SF-DMC conducted at 298,308 , and $328 \mathrm{~K}$.

Modeling of the experimental data using appropriate isotherm model is often used for prediction of the adsorption mechanism. In this study, Langmuir, and Freundlich models were fitted to the adsorption isotherms, which can be expressed as equation (8) and (9) (Hu et al., 2021):

$$
Q_{e}=\frac{Q_{m} K_{L} C_{e}}{1+K_{L} C_{e}}
$$

$$
Q_{e}=K_{F} C_{e}^{1 / n}
$$


where $Q_{e}(\mathrm{mg} / \mathrm{g})$ and $C_{e}(\mathrm{mg} / I)$ are the equilibrium adsorption capacity and equilibrium concentration, $Q_{m}$ $(\mathrm{mg} / \mathrm{g})$ is the maximum adsorption capacity.

The isotherm constants obtained in this study are given in Table 2. Langmuir model have highest $R^{2}$ value (>0.99) at all temperatures, which suggested the adsorption of IC formed a monolayer on SF-DMC (Yang et al., 2021). The theoretical maximum adsorption capacity of IC onto SF-DMC was from 709.22 to $892.86 \mathrm{mg} / \mathrm{g}$ at temperature ranged from 298 to $328 \mathrm{~K}$. In addition, it is observed that the adsorption capacity is negative correlated with temperature. According to Freundlich model, constant $n$ gives an idea about the favor of the adsorption process. The $\mathrm{n}$ is greater than 1 , indicating that IC was very favorable adsorbed by the SF-DMC (Hossain et al., 2021).

The maximum adsorption capacities of SF-DMC for IC were compared with other reported adsorbents given in Table 3. The SF-DMC had higher adsorption capacities than most of the other adsorbents. The small specific gravity and fiber diameter of SF combined with the advantage of RIGP, causing the large amounts of DMC monomer onto the surface of SF, which made SF-DMC very suitable for IC dye removal from aqueous solution.

Table 2

Key parameters and correlation coefficients of isotherm models for IC adsorption by SF-DMC

\begin{tabular}{|lllllll|}
\hline Temperature $\left({ }^{\circ} \mathrm{C}\right)$ & \multicolumn{2}{l}{ Langmuir } & \multicolumn{4}{l|}{ Freundlich } \\
& $\mathrm{Q}_{\mathrm{m}}$ & $\mathrm{K}_{\mathrm{L}}$ & $\mathrm{R}^{2}$ & $\mathrm{~K}_{\mathrm{F}}$ & $\mathrm{n}$ & $\mathrm{R}^{2}$ \\
\hline $298 \mathrm{~K}$ & 892.86 & 0.0225 & 0.9986 & 398.25 & 8.2977 & 0.9827 \\
\hline $308 \mathrm{~K}$ & 793.65 & 0.0292 & 0.9984 & 456.66 & 12.898 & 0.9000 \\
\hline $323 \mathrm{~K}$ & 709.22 & 0.0844 & 0.9999 & 569.89 & 32.237 & 0.9350 \\
\hline
\end{tabular}


Table 3

comparisons of adsorption capacity of SF-DMC with other available adsorbents.

\begin{tabular}{|lll|}
\hline Adsorbent & $\begin{array}{l}\mathbf{Q}_{\mathbf{m a x}} \\
\mathbf{( m g / g )}\end{array}$ & Reference \\
\hline Brazil nut shells & 1.09 & (Brito et al., 2009) \\
\hline Pistia stratiotes dry biomass & 41.2 & (Ferreira et al., 2019) \\
\hline Rice Husk Ash & $29.3-65.9$ & $\begin{array}{l}\text { (Lakshmi et al., } \\
\text { 2019) }\end{array}$ \\
\hline Mg/Fe LDH & 62.8 & (Ahmed et al., 2021) \\
\hline Chitosan aerogels & 168.6 & (Luna et al., 2019) \\
\hline Activated Carbon & 298.3 & (Zahia et al., 2019) \\
\hline Nanofiber memebranes & 266.8 & (Li et al., 2012) \\
\hline $\begin{array}{l}\text { carbonaceous nanofillers (graphite, graphene and graphene } \\
\text { Oxide) }\end{array}$ & 380 & (Galzerano et al., \\
\hline chitosan/graphene oxide aerogels & 534.4 & 2021) \\
\hline CS/STPP & 500 & (Luna et al., 2019) \\
\hline CS/ß-CD STPP & 1000 & (Kekes et al., 2020) \\
\hline SF-DMC & $709.22-$ & This paper \\
\hline
\end{tabular}

\subsubsection{Thermodynamics: effect of temperature on adsorption}

A series of adsorption experiments are conducted at 298-323 $\mathrm{K}$ to determine the adsorption was endothermic or exothermic in nature. The change in free energy $(\Delta G)$, enthalpy $(\Delta H)$, and entropy $(\Delta S)$ for the IC adsorption process are evaluated by Equation (10) to (11) (Mladenovic et al., 2021)

$\ln K_{\mathrm{d}}=\frac{\Delta S}{R}-\frac{\Delta H}{R T}$

$\Delta \mathrm{G}=\Delta \mathrm{H}-\mathrm{T} \Delta \mathrm{S}(11)$

where, $K_{d}$ is the equilibrium constant obtained from $Q_{e} / C_{e}, R$ is universal gas constant $(8.3144 \mathrm{~J} / \mathrm{mol} \times \mathrm{K})$ and $\mathrm{T}$ is the temperature $(\mathrm{K})$.

Figure 6 (d) shows the linear plot of thermodynamics at different initial concentration. The values of $\Delta \mathrm{H}$, $\Delta S$ and $\Delta G$ at different temperature were calculated from the slope and intercept by the linear plot and listed in Table 4. $\Delta \mathrm{G}<0, \Delta \mathrm{H}<0$ means that the IC adsorption by SF-DMC was a spontaneous and exothermic reaction. The $\Delta G$ values decreased as the adsorption temperature increasing, which means that the adsorption was more favorable at lower temperature (Ata et al, 2012). The result was consistent with the results of Langmuir model. 
Table 4

Thermodynamic parameters of the adsorption of IC on SF-DMC

\begin{tabular}{|llllll|}
\hline $\mathrm{C}_{0}(\mathrm{mg} / \mathrm{L})$ & $\boldsymbol{\Delta H}(\mathrm{KJ} / \mathrm{mol})$ & $\Delta S(\mathrm{~J} / \mathrm{mol} / \mathrm{K})$ & \multicolumn{4}{c|}{$\Delta \mathrm{G}(\mathrm{KJ} / \mathrm{mol})$} \\
\cline { 3 - 6 } & & & $\mathbf{2 9 8 K}$ & $\mathbf{3 0 8 K}$ & $\mathbf{3 2 3 K}$ \\
\hline 300 & -5.35 & -4.66 & -3.96 & -3.91 & -3.84 \\
\hline 500 & -6.23 & -14.14 & -2.02 & -1.87 & -1.66 \\
\hline 600 & -10.42 & -29.78 & -1.55 & -1.25 & -0.80 \\
\hline 800 & -10.76 & -33.05 & -0.91 & -0.58 & -0.08 \\
\hline
\end{tabular}

\subsubsection{Effect of $\mathrm{NaCl}$ Concentration}

The effect of $\mathrm{NaCl}$ on the adsorption performance is shown in Figure 7 (a). The initial concentration of the IC was $100 \mathrm{mg} / \mathrm{L}$. $C_{\mathrm{IC}} / C_{\mathrm{NaCl}}$ represents the molar concentration ratio of IC/ $\mathrm{NaCl}$. With increasing molar concentration of $\mathrm{NaCl}$, the adsorption capacity of IC was little decreased. When the concentration of $\mathrm{NaCl}$ was 1000 times that of the IC, the adsorption capacity was $61.8 \%$ of the adsorption capacity without $\mathrm{NaCl}$.

\subsubsection{Regeneration and Reusability}

The adsorption-desorption experiments were carried out for six cycles and shown in Figure 7 (b). After full adsorption ( $0.02 \mathrm{~g}$ SF-DMC added to $100 \mathrm{~mL}$ of $100 \mathrm{mg} / L \mathrm{IC}$ ), the IC loaded SF-DMC was regenerated using $\mathrm{HCl}$ at different concentration. The desorption (\%) by $1 \mathrm{M} \mathrm{HCl}$ was $75 \%$, and nearly $100 \%$ by $2 \mathrm{M}$ $\mathrm{HCl}$. So, $2 \mathrm{M} \mathrm{HCl}$ was selected to regenerate SF-DMC for further cycle adsorption. After 6 adsorptiondesorption cycles, the removal of IC still remained $95 \%$ of the first use. The results suggested that $2 \mathrm{M} \mathrm{HCl}$ is a good elution solution and that the SF-DMC can be used repeatedly for IC removal.

\subsubsection{Selective adsorption}

It is essential to investigate the selective adsorption performance, thus to well understand the relationship between the adsorbent and dyes to guide the design and fabrication. The competitive adsorption of IC and methyl orange $(\mathrm{MO})$ in binary mixture solution was investigated. Figure 8 (a) shows the UV-vis spectra of IC and MO. The absorption of IC at $\lambda_{\max } 468 \mathrm{~nm}$ is negligible compared to MO and the absorption of $\mathrm{MO}$ at $610 \mathrm{~nm}$ is negligible compared to IC. The selectivity coefficient $\alpha_{\text {IC / MO }}$ was calculated using equation (12) (Lin et al., 2015; Zhou et al., 2018):

$$
\alpha_{\mathrm{IC} / \mathrm{MO}}=\left(\frac{\mathrm{Q}_{\mathrm{IC}}}{\mathrm{Q}_{\mathrm{MO}}}\right)\left(\frac{\mathrm{C}_{\mathrm{MO}}}{\mathrm{C}_{\mathrm{IC}}}\right)
$$


where $Q_{\mathrm{i}}$ and $C_{\mathrm{i}}(\mathrm{i}=\mathrm{IC}$ or $\mathrm{MO})$ are the adsorption amounts $(\mathrm{mg} / \mathrm{g})$ of $\mathrm{i}$, and the equilibrium concentrations $(\mathrm{mg} / \mathrm{L})$.

The $\alpha_{\mathrm{IC} / \mathrm{MO}}$ values of SF-DMC for IC versus $\mathrm{MO}$ adsorption at different molar concentration ratio are shown in Figure 8. (b). $\alpha_{\mathrm{IC} / \mathrm{MO}}$ decreased when the molar ratio of $\mathrm{MO}$ increased and reached 72.55 at the molar concentration ratio 1:1. $\alpha_{\text {IC / MO }}$ was 11.29 when the molar ratio of IC/MO was 1:5, indicating that SF-DMC have more preferential adsorption for IC than MO. The electrostatic attraction between the quaternary ammonium group of SF-DMC and the sulfonic acid group of anion dyes IC molecule induced the adsorption. IC molecules had two sulfonic acid groups while MO had only one, which caused the competitive adsorption for IC than MO.

\section{Conclusion}

SF-DMC was synthesized by one-step grafting DMC onto SF using electron beam radiation. The results showed that SF was successfully quaternized. The maximum GY value obtained $73 \%$ at $60 \mathrm{kGy}$. The SFDMC have good adsorption performance to IC such as $\mathrm{pH}$ independent, fast adsorption rate, high adsorption capacity, selective adsorption and repeated use. The adsorption kinetics and isotherms of SFDMC were well obeyed the pseudo-second-order kinetics and Langmuir model respectively. The theoretical maximum adsorption capacity of IC onto SF-DMC was from 709.22 to $892.86 \mathrm{mg} / \mathrm{g}$. The IC adsorption by SF-DMC was a spontaneous and exothermic, which was more favorable at lower temperature. SF-DMC have more preferential adsorption for IC than MO with a selectivity coefficient 72.55 at the molar ratio $1: 1$ of IC than MO. SF-DMC can be efficiently regenerated by $2 \mathrm{M} \mathrm{HCl}$ and repeated use at least for 6 times without the adsorption capacity obvious decrease.

\section{Declarations}

\section{Acknowledgements}

This work was supported by National Natural Science Foundation of China $(11875138,11905070)$; Natural Science Foundation of Hubei Province, China (2020CFB852).

Conflict of interest The authors have no competing interests to declare that are relevant to the content of this article.

\section{References}

1. Ahmed MA, Brick AA, Mohamed AA (2017) An efficient adsorption of indigo carmine dye from aqueous solution on mesoporous $\mathrm{Mg} / \mathrm{Fe}$ layered double hydroxide nanoparticles prepared by controlled sol-gel route. Chemosphere 174:280-288.

https://doi.org/10.1016/j.chemosphere.2017.01.147

2. Ahmad MB, Soomro U, Muqeet M, Ahmed Z (2021) Adsorption of Indigo Carmine dye onto the surface-modified adsorbent prepared from municipal waste and simulation using deep neural 
network. J Hazard Mater 408:124433. https://doi.org/10.1016/j.jhazmat.2020.124433

3. Ata S, Din MI, Rasool A, Qasim I, Mohsin IU (2012) Equilibrium, Thermodynamics, and Kinetic Sorption Studies for the Removal of Coomassie Brilliant Blue on Wheat Bran as a Low-Cost Adsorben. J Anal Methods Chem 2:405980. http://dx.doi.org/10.1155/2012/405980

4. Bai Z, Liu Q, Song D, Zhang H, Liu J, Chen R (2020) Preparation of a 3D multi-branched chelate adsorbent for high selective adsorption of uranium(VI): Acrylic and diaminomaleonitrile functionalized waste hemp fiber. React Funct Polym 149:104512. https://doi.org/10.1016/j.reactfunctpolym.2020.104512

5. Borba C, Cba V, Oliveira, Silva P (2020) Production of thermostable fungal amylase and its application in the discoloration of indigo carmine. Int J Develop Res 10:37660-37667. https://doi.org/10.37118/ijdr.19329.07.2020

6. Brito S, Andrade H, Soares LF (2009) Brazil nut shells as a new biosorbent to remove methylene blue and indigo carmine from aqueous solutions. J Hazard Mater 174:84-92. https://doi.org/10.1016/j.jhazmat.2009.09.020

7. Candido ICM, Pires ICB, Oliveira HPD (2021) Natural and Synthetic Fiber-based Adsorbents for Water Remediation. CLEAN-Soil Air Water 49:2000189. https://doi.org/10.1002/clen.202000189

8. Chattopadhyay D, Umrigar K (2017) Chemical Modification of Waste Cotton Linters for Oil Spill Cleanup Application. J Inst Eng India Ser E 98:103-120. https://doi.org/10.1007/s40034-017-0107-y

9. Chokshi S, Parmar V, Gohil P, Chaudhary V (2020) Chemical Composition and Mechanical Properties of Natural Fibers. J Nat Fib 3:1-12. https://doi.org/10.1080/15440478.2020.1848738

10. Chowdhury MF, Khandaker S, Sarker F, Islam A, Rahman MT, Awual MF (2020) Current treatment technologies and mechanisms for removal of indigo carmine dyes from wastewater: A review. $J$ Molecul Liq 318:114061. https://doi.org/10.1016/j.molliq.2020.114061

11. Cui F, Li H, Chen C et al (2021) Cattail fibers as source of cellulose to prepare a novel type of composite aerogel adsorbent for the removal of enrofloxacin in wastewater. Int $\mathrm{J}$ Biol Macromol 191:171-181. https://doi.org/10.1016/j.ijbiomac.2021.09.022

12. Dong Z, Wang Y, Wen D, Peng J, Zhao L, Zhai ML (2021) Recent Progress in Environmental Applications of Functional Adsorbent Prepared by Radiation techniques: A review. J Hazard Mater 424:126887. https://doi.org/10.1016/j.jhazmat.2021.126887

13. Du JF, Yang X, Xiong H, Dong Z, Wang Z, Chen Z, Zhao L (2021) Ultrahigh Adsorption Capacity of Acrylic Acid-Grafted Xanthan Gum Hydrogels for Rhodamine B from Aqueous Solution. J Chem Engineer Data 66:1264-1272. https://doi.org/10.1021/acs.jced.0c00850

14. Du JF, Dong Z, Pi XY, Yang X, Zhao L (2019a) Fabrication of Cotton Linter-Based Adsorbents by Radiation Grafting Polymerization for Humic Acid Removal from Aqueous Solution. Polymers 11:962. https://doi.org/10.3390/polym11060962

15. Du JF, Dong Z, Lin Z, Yang X, Zhao L (2019b) Radiation Synthesis of Pentaethylene Hexamine Functionalized Cotton Linter for Eective Removal of Phosphate: Batch and Dynamic Flow Mode Studies. Materials 12:3393. https://doi.org/10.3390/ma12203393 
16. Du JF, Dong Z, Yang X, Zhao L (2018) Facile fabrication of sodium styrene sulfonate-grafted ethylene- vinyl alcohol copolymer as adsorbent for ammonium removal from aqueous solution. Environ Sci Pollut Res 25:27235-27244. https://doi.org/10.1007/s11356-018-2750-3

17. Du JF, Dong Z, Yang X, Zhao L (2020) Radiation grafting of dimethylaminoethyl methacrylate on cotton linter and subsequent quaternization as new eco-friendly adsorbent for phosphate removal. Environ Sci Pollut Res 27:24558-24567. https://doi.org/10.1007/s11356-020-08712-5

18. Ferreira RM, Oliveira NM, Lima LLS (2019) Adsorption of indigo carmine on Pistia stratiotes dry biomass chemically modified. Environ Sci Pollut Res 26:28614-28621. https://doi.org/10.1007/s11356-018-3752-x

19. Filho AS, Parveen S, Rana S (2020) Mechanical and micro-structural investigation of multi-scale cementitious composites developed using sisal fibres and microcrystalline cellulose. Ind Crop Prod 158:112912. https://doi.org/10.1016/j.indcrop.2020.112912

20. Gao DW, Hu Q, Pan H (2015) High-capacity adsorption of aniline using surface modification of lignocellulose-biomass jute fibers. Bio Technol 193:507-512. https://doi.org/10.1016/j.biortech.2015.06.138

21. Gopi S, Balakrishnan P, Pius A, Thomas S (2017) Chitin nanowhisker (ChNW)-functionalized electrospun PVDF membrane for enhanced removal of Indigo carmine. Carbohyd Polym 165:115122. https://doi.org/10.1016/j.carbpol.2017.02.046

22. Hadid M, Noukrati H, Youcef H, Barroug A, Sehaqui H (2021) Phosphorylated cellulose for water purification: a promising material with outstanding adsorption capacity towards methylene blue. Cellulose 28:7893-7908. https://doi.org/10.1007/s10570-021-04012-4

23. Hu T, Hu X, Tang C et al (2021) Adsorbent grafted on cellulose by in situ synthesis of EDTA-like groups and its properties of metal ion adsorption from aqueous solution. Cellulose https://doi.org/10.1007/s10570-021-04324-5

24. Huang Z, Wu P, Yin Y et al (2021) Preparation of cotton fibers modified with aromatic heterocyclic compounds and study of $\mathrm{Cr}(\mathrm{VI})$ adsorption performance. Cellulose 28:11037-11049. https://doi.org/10.1007/s10570-021-04217-7

25. Hossain MY, Zhu W, Pervez MN, Yang X, Sarker S, Hassan MM, Hoque MIH, Zaddeo V, Cai Y (2021) Adsorption, kinetics, and thermodynamic studies of cacao husk extracts in waterless sustainable dyeing of cotton fabric. Cellulose 28:2521-2536. https://doi.org/10.1007/s10570-020-03662-0

26. Kekes T, Tzia C (2020) Adsorption of indigo carmine on functional chitosan and $\beta$ cyclodextrin/chitosan beads: Equilibrium, kinetics and mechanism studies. J Environ Manage 262:110372. https://doi.org/10.1016/j.jenvman.2020.110372

27. Lakshmi UR, Srivastava VC, Mall ID, Lataye DH (2019) Rice husk ash as an effective adsorbent:evaluation of adsorptive characteristics for indigo carmine dye. J Environ Manage 90:710-720. https://doi.org/10.1016/j.jenvman.2008.01.002

28. Lei J, Zhang Y, He P (2021) An a-Fe2O3/Circulating Fluidized Bed Fly Ash Based Geopolymer Composite Anode for Electrocatalytic Degradation of Indigo Carmine Dye Wastewater. J Renewable 
Mater 9:2277-2289. https://doi.org/10.32604/jrm.2021.015824

29. Luna MSD, Ascione C, Santillo C, Verdolotti L, Ambrosio L (2019) Optimization of dye adsorption capacity and mechanical strength of chitosan aerogels through crosslinking strategy and graphene oxide addition. Carbohyd Polym 211:195-203. https://doi.org/10.1016/j.carbpol.2019.02.002

30. Li W, Zuo P, Xu D, Xu Y, Wang K, Bai Y, Ma H (2017) Tunable adsorption properties of bentonite/carboxymethyl cellulose-g-poly(2-(dimethylamino) ethyl methacrylate) composites towards anionic dyes. Chem Eng Res Des 124:260-270. https://doi.org/10.1016/j.cherd.2017.06.034

31. Li L, Chen R, Li Y, Xiong T, Li Y (2020) Novel cotton fiber-covalent organic framework hybrid monolith for reversible capture of iodine. Cellulose 27:5879-5892. https://doi.org/10.1007/s10570-02003189-4

32. Lin H, Wei W, Wu X, Zhou T, Mao J, Yun YS (2015) Selective recovery of Pd(II) from extremely acidic solution using ion-imprinted chitosan fiber: Adsorption performance and mechanisms. J Hazard Mater 299:10-17. http://dx.doi.org/10.1016/j.jhazmat.2015.05.050

33. Liu Y, Peng Y, Zhang T et al (2018) Superhydrophobic, ultralight and flexible biomass carbon aerogels derived from sisal fibers for highly efficient oil-water separation. Cellulose 25:3067-3078. https://doi.org/10.1007/s10570-018-1774-7

34. Melike DO, Evan F, Vaidya UK (2018) Applicability of Industrial Sisal Fiber Waste Derived Activated Carbon for the Adsorption of Volatile Organic Compounds (VOCs). Fib Polym 19:805-811. https://doi.org/10.1007/s12221-018-7866-z

35. Meng G, Yan J, Wu J, Zhang W, Guo X (2020) Thiol-ene Click Chemistry Construct Superhydrophobic Cotton Fabric for High-efficiency Water-in-oil Emulsion Separation. Fiber Polym 21:245-251. https://doi.org/10.1007/s12221-020-9191-6

36. Mladenovic N, Petkovska J, Dimova V, Dimitrovsk D, Jordanov I (2021) Circular economy approach for rice husk modification: equilibrium, kinetic, thermodynamic aspects and mechanism of Congo red adsorption. https://doi.org/10.1007/s10570-021-04312-9. Cellulose

37. Mostofa A, Zheng J, Majumder M (2021) Interfacial properties of trithiocyanuric acid functionalized cellulose nanofibers for efficient recovery of gold ions from aqueous solution. Cellulose 28:937-947. https://doi.org/10.1007/s10570-020-03575-y

38. Pang D, Wang CC, Liu W, Fu H, Zhao C (2020) Superior removal of inorganic and organic arsenic pollutants from water with MIL-88A(Fe) decorated on cotton fibers. Chemosphere 254:126829. https://doi.org/10.1016/j.chemosphere.2020.126829

39. Secula MS, Vajda A, Cagnon B, Warmont F, Mamaliga I (2020) Photo-Fenton-peroxide process using FE (II)-embedded composites based on activated carbon: Characterization of catalytic tests. Can J Chem Eng 98:650-658. https://doi.org/10.1002/cjce.23662

40. Silva C, Lima A, Moreto JA (2020) Influence of plasma treatment on the physical and chemical properties of sisal fibers and environmental application in adsorption of methylene blue. Mater Today Commun 23:101140. https://doi.org/10.1016/j.mtcomm.2020.101140 
41. Shao X, Wang J, Liu Z et al (2021) Cellulose based cation-exchange fiber as filtration material for the rapid removal of methylene blue from wastewater. Cellulose 28:9355-9367.

https://doi.org/10.1007/s10570-021-04103-2

42. Shu Z, Wu H, Lin H (2016) Decolorization of Remazol Brilliant Blue R using a novel acyltransferaseISCO (in situ chemical oxidation) coupled system. Biochem Engineer J 115:56-63. https://doi.org/10.1016/j.bej.2016.08.008

43. Song MK, Lee BT (2019) Synthesis of CH3l-quaternized polypropylene nonwoven fiber grafted with imidazole (PP-g-Vim) to adsorb vapor phase ammonia. Chemosphere 233:660-666. https://doi.org/10.1016/j.chemosphere.2019.05.106

44. Tesfamariam T, Wangatia LM, Esayas $A$ (2019) Removal of $\mathrm{Pb}(\mathrm{II})$ from aqueous media using adsorption onto polyaniline coated sisal fibers. J Vinyl Addit Techn 25:189-197. https://doi.org/10.1002/vnl.21652

45. Taleb M, Mahmoud GA, Elsigeny SM, Hegazy ESA (2008) Adsorption and desorption of phosphate and nitrate ions using quaternary (polypropylene-g-N,N-dimethylamino ethylmethacrylate) graft copolymer. J Hazard Mater 159:372-379. https://doi.org/10.1016/j.jhazmat.2008.02.028

46. Udoetok IA, Wilson LD, Headley JV (2016) Quaternized Cellulose Hydrogels as Sorbent Materials and Pickering Emulsion Stabilizing Agents. Materials 9:645. https://doi.org/10.3390/ma9080645

47. Wang F, Xue B, Zhou S (2019) Synthesis and property of novel anion exchange membrane based on poly(aryl ether sulfone)s bearing piperidinium moieties. J Membrane Sci 591:117334. https://doi.org/10.1016/j.memsci.2019.117334

48. Wu S, Zhang J, Li C et al (2021) Characterization of potential cellulose fiber from cattail fiber: A study on micro/nano structure and other properties. Int J Biol Macromol 193:27-37. https://doi.org/10.1016/j.jibiomac.2021.10.088

49. Yang X, Zhu W, Song Y, Zhuang H, Tang H (2021) Removal of cationic dye BR46 by biochar prepared from Chrysanthemum morifolium Ramat straw: A study on adsorption equilibrium, kinetics and isotherm. J Mol Liq 340:116617. https://doi.org/10.1016/j.molliq.2021.116617

50. Yang L, Yang S, Wang C (2015) Facile synthesis of poly(DMC-co-HPA) hydrogels via infrared laser ignited frontal polymerization and their adsorption-desorption switching performance. J Polym Sci Polym Chem 53:2085-2093. https://doi.org/10.1002/pola.27701

51. Zheng $Y$, Wang J, Wang A (2021) Recent advances in the potential applications of hollow kapok fiberbased functional materials. Cellulose 28:5269-5292. https://doi.org/10.1007/s10570-021-03834-6

52. Zhang Y, Xu L, Zhao L, Peng J, Li C, Li J, Zhai ML (2012) Radiation synthesis and $\mathrm{Cr}(\mathrm{VI})$ removal of cellulose microsphere adsorbent. Carbohyd Poly 88:931-938.

https://doi.org/10.1016/j.carbpol.2012.01.040

53. Zhou X, Lai C, Huang D, Zeng G, Chen L, Qin L, Zhou C (2018) Preparation of water-compatible molecularly imprintedthiol-functionalized activated titanium dioxide: Selective adsorptionand efficient photodegradation of 2, 4-dinitrophenol in aqueoussolution. J Hazard Mater 346:113-123. https://doi.org/10.1016/j.jhazmat.2017.12.032 
Figures

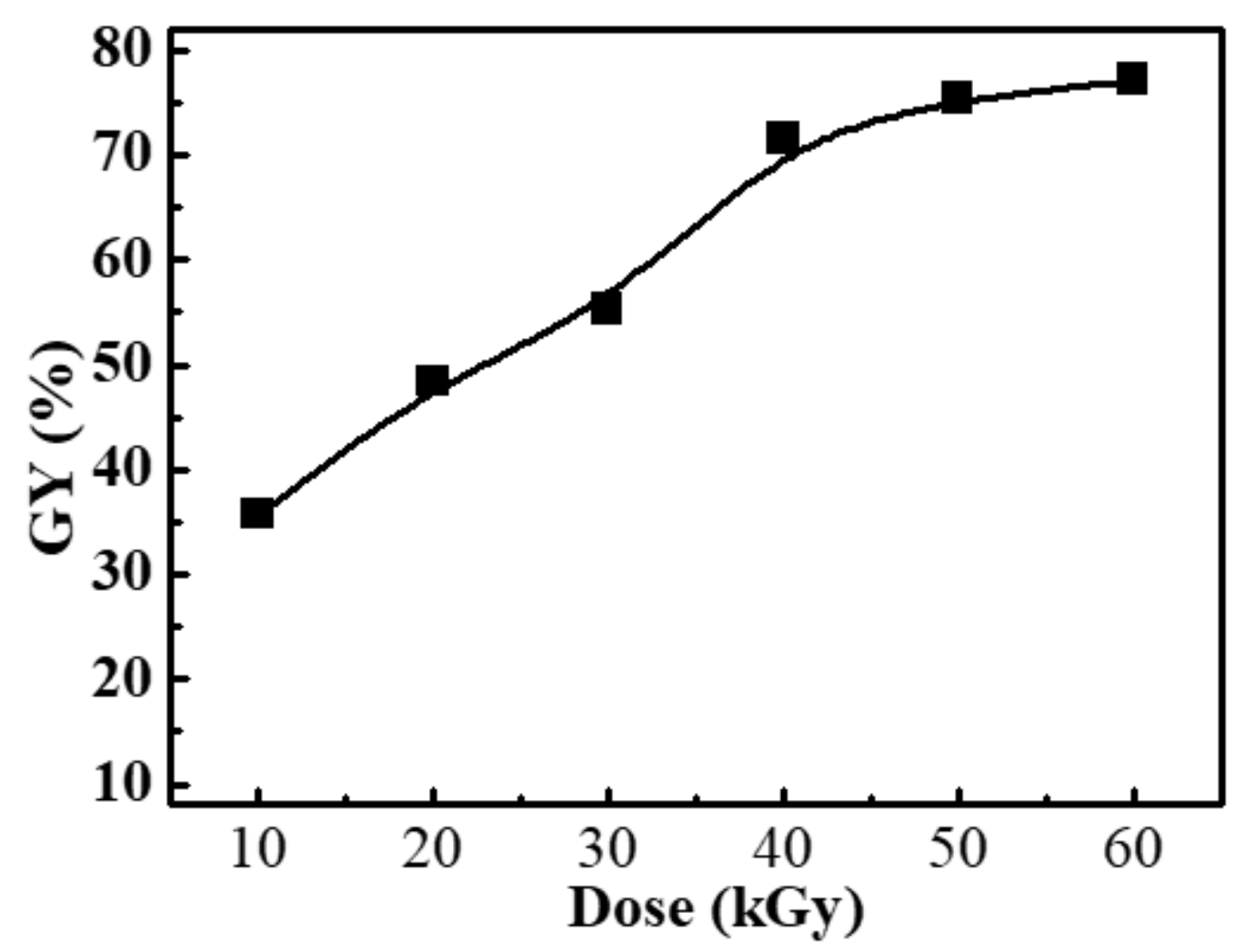

Figure 1

Effect of radiation dose on GY
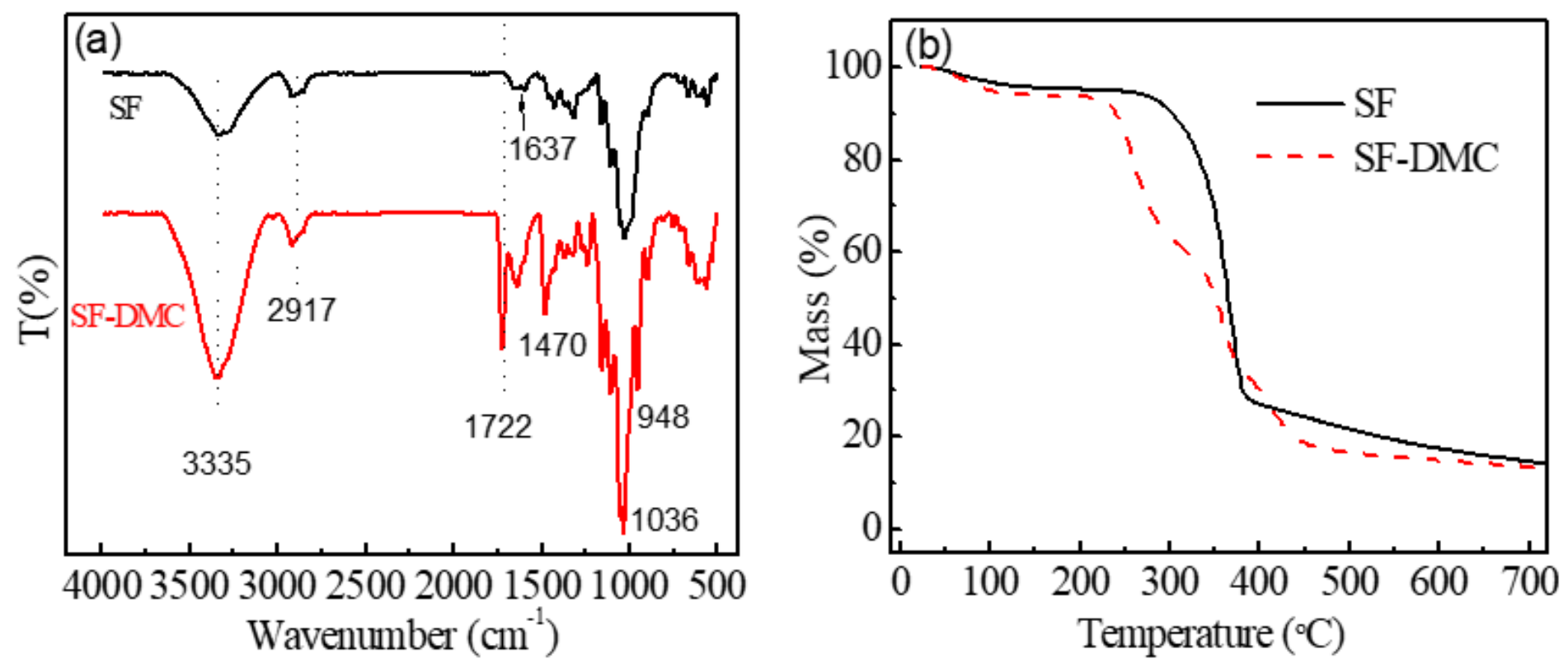
Figure 2

FTIR spectra (a) and TG analysis (b) of SF and SF-DMC

\section{Figure 3}

Surface morphology of SF (a) and SF-DMC (b)

Figure 4

Effect of pH for IC adsorption (a) and Zeta potential of SF (b) 

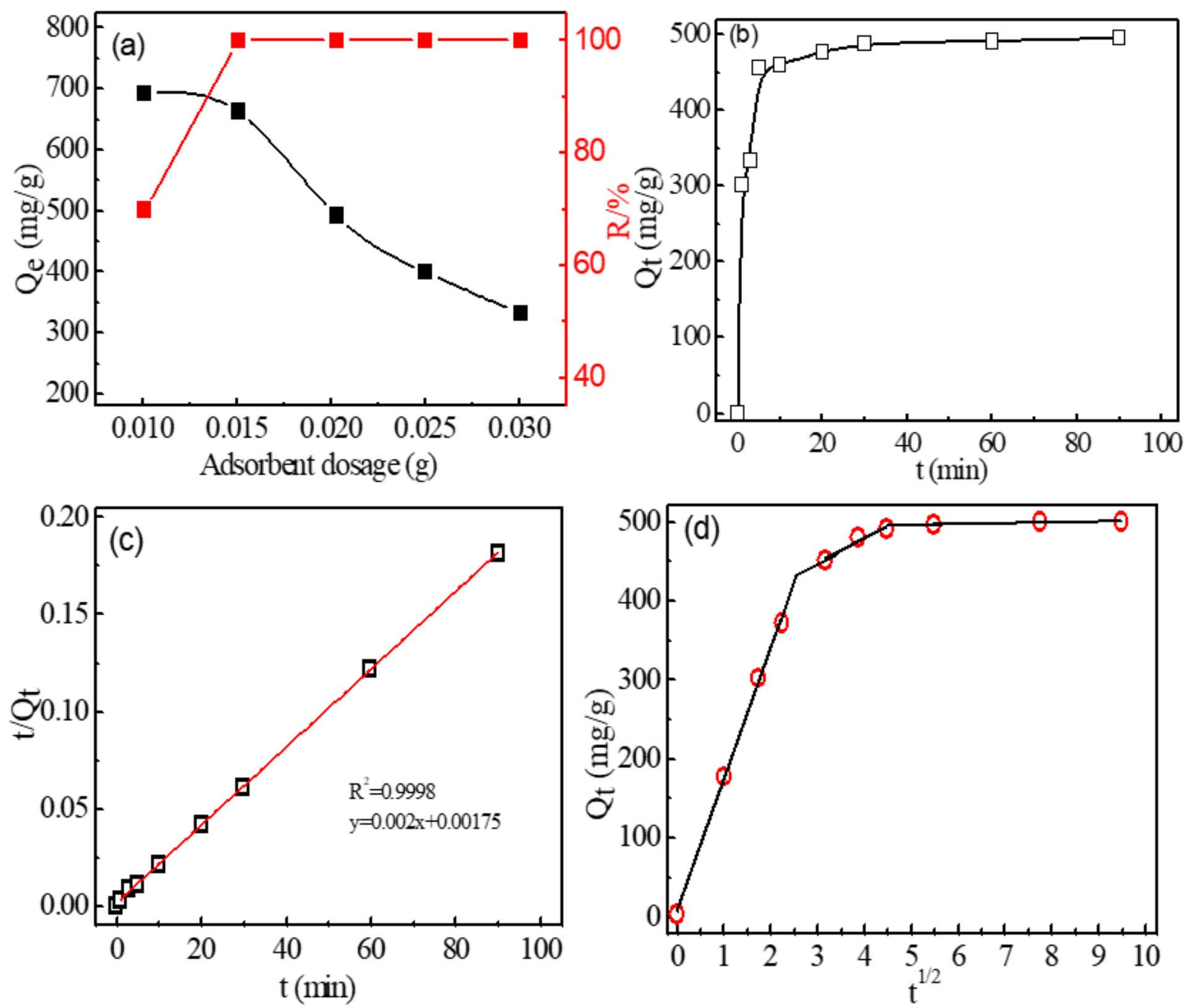

Figure 5

Effect of dosage on the adsorption (a); effect of adsorption time on adsorption IC (b); pseudo secondorder (c) and intra-particle model (d) 

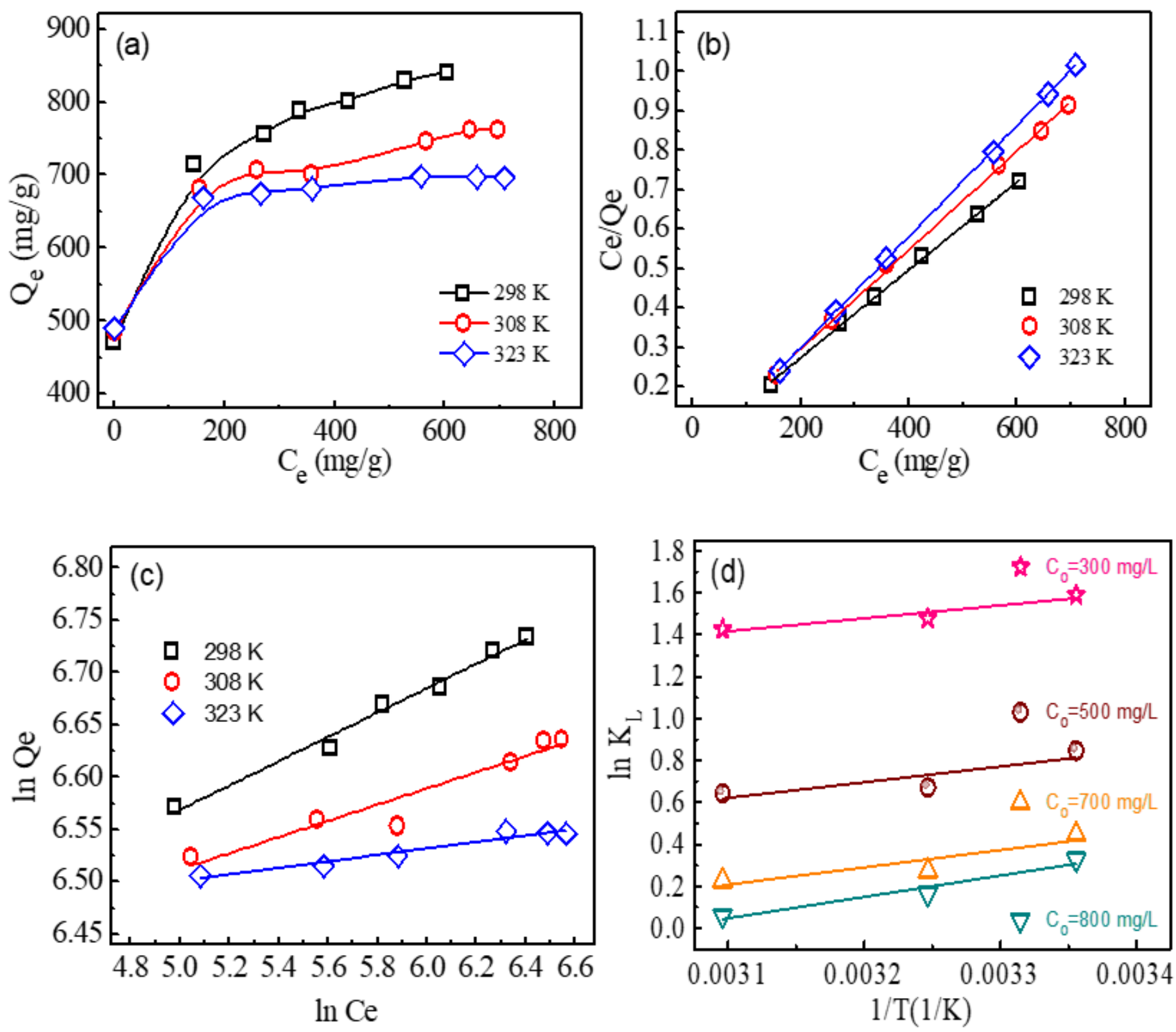

Figure 6

Adsorption isotherms of IC onto SF-DMC; effect of initial concentration (a); Langmuir model (b) ; Freundlich model (c) ; and Van't Hoff plots at different concentration (d) 

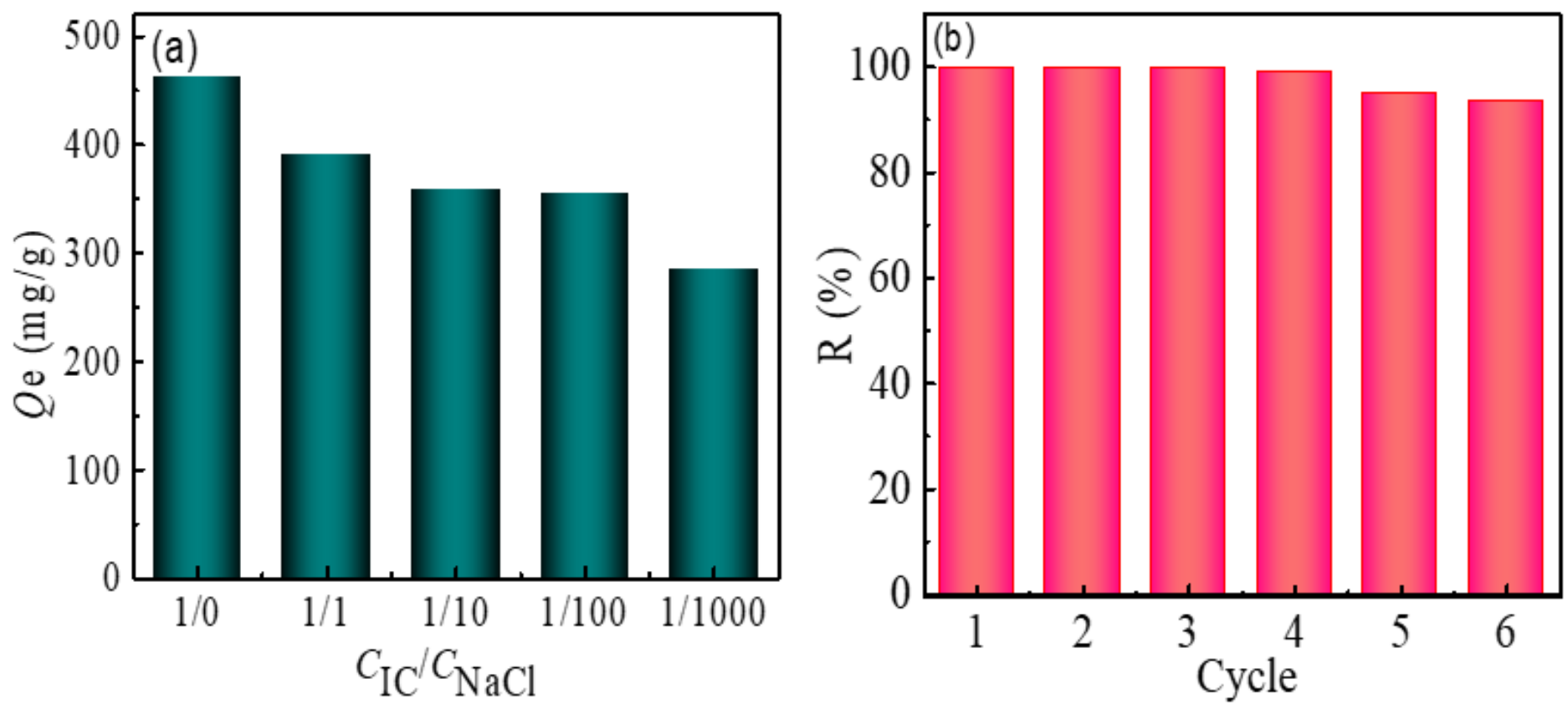

Figure 7

Effect of $\mathrm{NaCl}$ on the adsorption capacity (a) and removal efficiency of IC after 6 times regeneration (b)

Figure 8

UV-vis spectra of IC and MO (a) and effect of IC/MO molar ratio on the selective adsorption (b). 